\title{
Original Scientific Reports: Clinicopathological Findings of Remnant Pancreatic Cancers in Survivors Following Curative Resections of Pancreatic Cancers
}

\author{
Shuji Suzuki ${ }^{1,2} \cdot$ Toru Furukawa $^{3} \cdot$ Nana Oshima $^{2} \cdot$ Wataru Izumo $^{2} \cdot$ \\ Kyoko Shimizu ${ }^{4} \cdot$ Masakazu Yamamoto $^{2}$
}

Published online: 20 November 2015

(c) The Author(s) 2015. This article is published with open access at Springerlink.com

\begin{abstract}
Background This retrospective study aimed to evaluate clinicopathological findings of remnant pancreatic cancers in survivors of invasive ductal adenocarcinomas of the pancreas (PDAC).

Methods A group of 23 patients out of 826 who had curative resections for PDAC between 1980 and 2011 was identified and treated for metachronous pancreatic cancer.

Results The following tubular adenocarcinomas were found at the first surgery: 3 well differentiated, 17 moderately differentiated, 1 papillary, and 1 poorly differentiated. Treatments for the remnant pancreas consisted of remnant pancreatectomy in 12 patients, chemotherapy in 6 , and the best supportive care in 5 . The mean time to treatment was 74.2 months. The 12 patients who received remnant resections had 10 PDACs and 2 intraductal papillary mucinous carcinomas. The median survival time was 31.6 months, and 8 patients are still alive.

Conclusions Long-term survivors after curative resection for pancreatic cancer should receive follow-up for remnant pancreatic cancer, and aggressive resection should be considered for more favorable prognosis of PDAC.
\end{abstract}

\section{Introduction}

Pancreatic cancer is known to have a high frequency of postoperative recurrences and a poor prognosis. Pancreatic cancer is now the fifth leading cause of cancer-related deaths in Japan [1], and most patients develop a recurrence of the same cancer within 1 or 2 years after tumor removal [2]. The

Shuji Suzuki

ssuzuki@tokyo-med.ac.jp

1 Department of Gastroenterological Surgery, Ibaraki Medical Center, Tokyo Medical University, 3-20-1 Chuo, Amimachi, Inashikigun, Ibaraki 300-0395, Japan

2 Department of Gastroenterological Surgery, Tokyo Women's Medical University, Tokyo, Japan

3 Institute for Integrated Medical Sciences, Tokyo Women's Medical University, Tokyo, Japan

4 Department of Gastroenterology, Tokyo Women's Medical University, Tokyo, Japan most frequent recurrence patterns for pancreatic cancer after resection are local recurrence, hepatic metastasis, and peritoneal dissemination [3-6]. The high frequency of reported recurrences has been attributed to malignant cells remaining on resected margins in up to $50 \%$ of cases even after macroscopically curative resection [7]. This R1-like situation could explain the high local recurrence rate [7]. Another reason is the presence of systemic occult disease at the time of operation in most of the patients, which could lead to distant metastasis in the liver (50\% of resected patients) or peritoneum $(25 \%)$ [5, 7-9].

Remnant pancreatic cancer sometimes appears in survivors after curative resection for invasive ductal adenocarcinoma of the pancreas (PDAC). However, there are few reports on the development of pancreatic cancer in the remnant pancreas after pancreatectomy [1], [10]. Consequently, the clinical characteristics of remnant pancreatic cancer after curative resection for PDAC are not well known. The aim of this study was to evaluate clinicopathological 
findings regarding remnant pancreatic cancer in PDAC survivors.

\section{Materials and methods}

Between 1980 and 2011 at the Department of Gastroenterological Surgery of Tokyo Women's Medical University, 826 patients who had curative resections for PDAC were studied retrospectively. The remnant pancreatic cancer was detected by means of the serum levels of carcinoembryonic antigen and CA19-9 as well as computed tomography (CT), abdominal ultrasonography, and magnetic resonance imaging (MRI).

The patients were followed up in the outpatient clinic of our hospital or a related hospital and clinic every 3-6 months, and most of the follow-up data collected from these clinical hospital files were studied. (They were evaluated by examination every 3-4 months in the outpatient clinic of our hospital and every 3-6 months in the related hospital and clinic.)

A remnant pancreatic cancer was defined by the following criteria: (1) pathologically negative surgical margins at the first surgery (R0 operation) without M1 but with extra regional lymph nodes according to the UICC. (2) No recurrent tumor detected by $\mathrm{CT}$ or MRI examination within 1 year after the first operation. (3) The tumor appeared to develop and exist in the remnant pancreas. Twenty-three patients $(2.8 \%)$ fulfilling these criteria were ultimately employed for this retrospective study (Table 1).

All of these 23 cases were pathologically confirmed by histological information to be PDAC with R0 treatment at the first operation. Clinicopathological features including sex, age, primary and secondary tumor characteristics, and long-term survival data were collected from hospital records. These factors related to the primary operation including sex, age, location, operation, degree of differentiation, tumor size, $\mathrm{N}$ of UICC (lymph node state), pancreatic duct margin, preoperative CA19-9 levels, perineural invasion, and postoperative adjuvant chemotherapy were analyzed using both univariate and multivariate analyses.

\section{Statistical analysis}

The survival times of unresected and resected patients were estimated using the Kaplan-Meier method and compared using the log-rank test. A univariate and multivariate Cox proportional hazards model was used to evaluate which factors demonstrated an independent effect on disease-free intervals (DFIs). $P$ values less than 0.05 were considered statistically significant. Analysis was performed using SPSS Statistics 22.0 (IBM Corp., Chicago, IL).

\section{Results}

At the first surgery, the tumor was located in the pancreatic head in 12 patients and in the pancreatic body in 11 patients. Pylorus-preserving pancreatoduodenectomy (PPPD) was performed in 8 patients, pancreatoduodenectomy (PD) in 3 patients, duodenum-preserving pancreatic head resection (DPPHR) in 1 patient, and distal pancreatectomy (DP) in 11 patients (Tables 1, 2). A well-differentiated tubular adenocarcinoma was detected in 3 patients, a moderately differentiated tubular adenocarcinoma in 18 patients, a papillary adenocarcinoma in 1 patient, and a poorly differentiated adenocarcinoma in 1 patient. These patients were classified into stages according to UICC classification as follows: 2 in IA, 2 in IB, 10 in IIA, 7 in IIB, and 2 in IV. All patients underwent curative resection. The median and mean DFIs for these patients were 53.6 and 74.2 months (range, 15-240), respectively. Regarding treatment procedures, 12 patients underwent total excision of the remnant pancreas, 6 received chemotherapy, and 5 received the best supportive care (BSC). The six patients treated with chemotherapy consisted of four who received chemotherapy after refusing surgery despite resectable PDAC and two with unresectable PDAC due to locally advanced tumors. The five BSC patients consisted of three with unresectable PDAC (2 with locally advanced tumor and 1 with liver metastasis) and two with resectable PDAC who refused surgery.

The pathological findings of the remnant pancreas in the 12 resected cases were PDAC in 10 patients and intraductal papillary mucinous carcinoma with an associated invasive carcinoma in 2 patients. The 12 patients were found to be in the following stages (UICC classification): 2 in 0,1 in IA, 3 in IIA, and 6 in IIB. The same histopathological features in specimens from the first and second operations were recognized in 8 of the $12(67 \%)$ cases. The mortality and morbidity rates of resected patients were 0 and $41.6 \%$, respectively. Complications were observed in five patients: 2 with delayed gastric emptying, 2 with intra-abdominal abscess, and 1 with sepsis. The average length of hospital stay was 34 days (13-70). No unresected patients had survived, and eight patients who underwent total excision of the remnant pancreas survived. The 5-year survival rate for all the 826 studied resected pancreatic cancer patients was $21.3 \%$. The mean and median survival times after the second operation were 23.7 (range, 1-90) and 31.6 months, respectively. The 1-year and 3-year survival rates and the median survival time were 45.5, $9.1 \%$, and 12 months for 


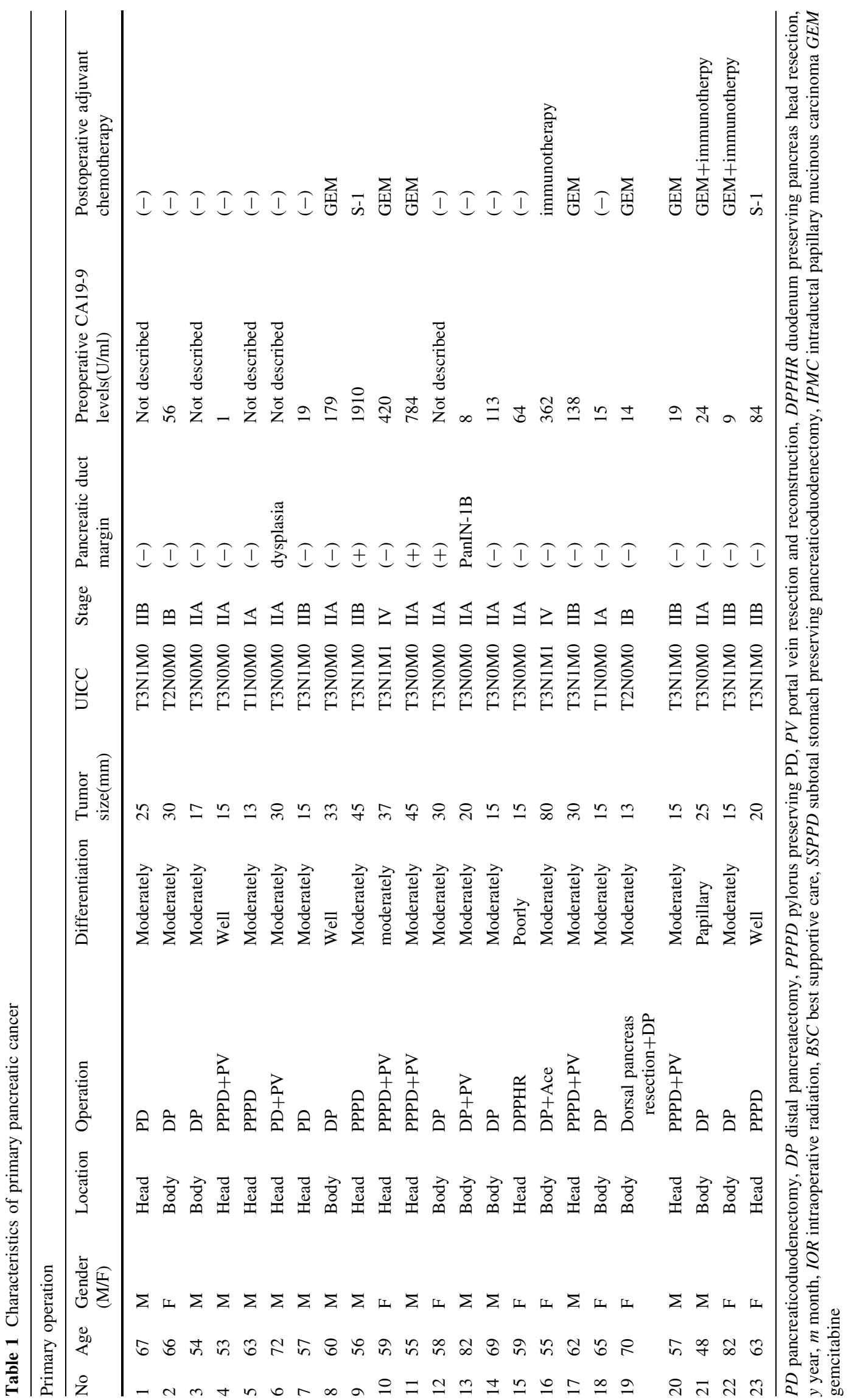


Table 2 Characteristics of remnant pancreatic cancer

\begin{tabular}{|c|c|c|c|c|c|c|c|}
\hline \multicolumn{8}{|c|}{ Remnant operation } \\
\hline No & DFI & Treatment & Differentiation & UICC & Stage & $\begin{array}{l}\text { Prognosis(after 2nd } \\
\text { operation) }\end{array}$ & $\begin{array}{l}\text { Recurrence } \\
\text { form }\end{array}$ \\
\hline 1 & 20 years & BSC(resection impossible) & $(-)$ & & & Death(6 m) & Peritoneum \\
\hline 2 & $\begin{array}{l}11 \text { year } \\
11 \text { month }\end{array}$ & Remnant pancreas resection $+\mathrm{PV}$ & Moderately & T3N1M0 & IIB & Death(11 month) & Peritoneum \\
\hline 3 & 9 year 5 month & Chemotherapy(resection possible) & $(-)$ & & & Death(3 year) & $\begin{array}{l}\text { Liver, } \\
\text { peritoneum }\end{array}$ \\
\hline 4 & 10 year 1 month & Chemotherapy(resection possible) & $(-)$ & & & $\begin{array}{l}\text { Death(1 year } \\
4 \text { month })\end{array}$ & $\begin{array}{l}\text { Liver, } \\
\text { peritoneum }\end{array}$ \\
\hline 5 & 10 year 2 month & BSC(resection impossible) & $(-)$ & & & Death(6 month) & $\begin{array}{l}\text { Liver, } \\
\text { peritoneum }\end{array}$ \\
\hline 6 & 9 year 9 month & BSC(resection impossible) & $(-)$ & & & Death(2 month) & $\begin{array}{l}\text { Liver, } \\
\text { peritoneum, } \\
\text { lung }\end{array}$ \\
\hline 7 & 9 year 2 month & $\begin{array}{l}\text { Remnant pancreas resection+remnant } \\
\text { stomach resection }+ \text { IOR }\end{array}$ & Moderately & T3N1M0 & IIB & Death(4 month) & Pleura \\
\hline 8 & 5 year 8 month & Remnant pancreas resection & Well & T1N0M0 & IA & Alive(7 year) & $(-)$ \\
\hline 9 & 6 year 3 month & Remnant pancreas resection & Moderately & T3N0M0 & IIA & $\begin{array}{l}\text { Alive }(1 \text { year } \\
3 \text { month })\end{array}$ & $(-)$ \\
\hline 10 & 4 year 5 month & Chemotherapy(resection possible) & $(-)$ & & & $\begin{array}{l}\text { Death }(1 \text { year } \\
6 \text { month })\end{array}$ & $\begin{array}{l}\text { Liver, } \\
\text { peritoneum }\end{array}$ \\
\hline 11 & 2 year 5 month & Chemotherapy(resection possible) & $(-)$ & & & Death(9 month) & $\begin{array}{l}\text { Liver, } \\
\text { peritoneum }\end{array}$ \\
\hline 12 & 2 year 5 month & Remnant pancreas resection & Moderately & T3N0M0 & IIA & $\begin{array}{l}\text { Death(2 year } \\
1 \text { month })\end{array}$ & Liver \\
\hline 13 & 3 year5 month & BSC(resection possible) & $(-)$ & & & Death(10 month) & $\begin{array}{l}\text { Liver, } \\
\text { peritoneum }\end{array}$ \\
\hline 14 & 3 year 3 month & Remnant pancreas resection $+\mathrm{PV}$ & Well & T3N1M0 & IIB & $\begin{array}{l}\text { Death }(2 \text { year } \\
6 \text { month })\end{array}$ & Liver, lung \\
\hline 15 & 2 year 9 month & Remnant pancreas resection & Poorly & T3N0M0 & IIA & $\begin{array}{l}\text { Alive( } 7 \text { year } \\
\quad 6 \text { month) }\end{array}$ & $(-)$ \\
\hline 16 & 2 year 6 month & $\begin{array}{l}\text { Remnant pancreas resection+remnant } \\
\text { stomach resection }\end{array}$ & IPMC & TisNOM0 & 0 & Alive(8 month) & $(-)$ \\
\hline 17 & 1year 3month & DP & Moderately & T3N1M0 & IIB & Alive(3 year) & Peritoneum \\
\hline 18 & 2 year 7 month & DPPHR & IPMC & TisN0M0 & 0 & $\begin{array}{l}\text { Alive( } 3 \text { year } \\
8 \text { month) }\end{array}$ & $(-)$ \\
\hline 19 & 2year 9 month & Chemoradiotherapy(resection impossible) & $(-)$ & & & Death(12 month) & Peritoneum \\
\hline 20 & 2 year 8 month & Remnant pancreas resection & Moderately & T3N1M0 & IIB & Alive(6 month) & $(-)$ \\
\hline 21 & 13 year 1 month & Chemoradiotherapy(resection impossible) & $(-)$ & & & $\begin{array}{l}\text { Dead(4 year } \\
5 \text { month) }\end{array}$ & Peritoneum \\
\hline 22 & 1 year 6 month & BSC(resection possible) & $(-)$ & & & $\begin{array}{l}\text { Dead(2 year } \\
2 \text { month) }\end{array}$ & Peritoneum \\
\hline 23 & 5 year 2 month & Remnant pancreas resection & Moderately & T3N1M0 & IIB & Alive(1 month) & $(-)$ \\
\hline
\end{tabular}

$D F I$ disease free interval $P D$ pancreaticoduodenectomy, $D P$ distal pancreatectomy, $P P P D$ pylorus preserving $P D, P V$ portal vein resection and reconstruction, $D P P H R$ duodenum preserving pancreas head resection, $y$ year, $m$ month, IOR intraoperative radiation, $B S C$ best supportive care, $S S P P D$ subtotal stomach preserving pancreaticoduodenectomy, IPMC intraductal papillary mucinous carcinoma IOR intraoperative radiation therapy

unresected patients, respectively, contrasting with 79.6, $53 \%$, and not obtained for resected patients, respectively ( $P=0.0049$ by log-rank test) (Fig. 1).

Recurrences were observed in 16 patients (13 with peritoneal dissemination [56.5\%], 9 with liver metastasis
[39.1\%], 2 with lung metastasis [8.7\%], and 1 with pleural metastasis [4.3\%]). A univariate analysis for DFI showed no significant difference by any of clinicopathological features. None of the lymph node state, degree of differentiation, and perineural invasion could predict 
Fig. 1 Kaplan-Meier curve for overall survival between resected and unresected patients for the remnant pancreatic cancer

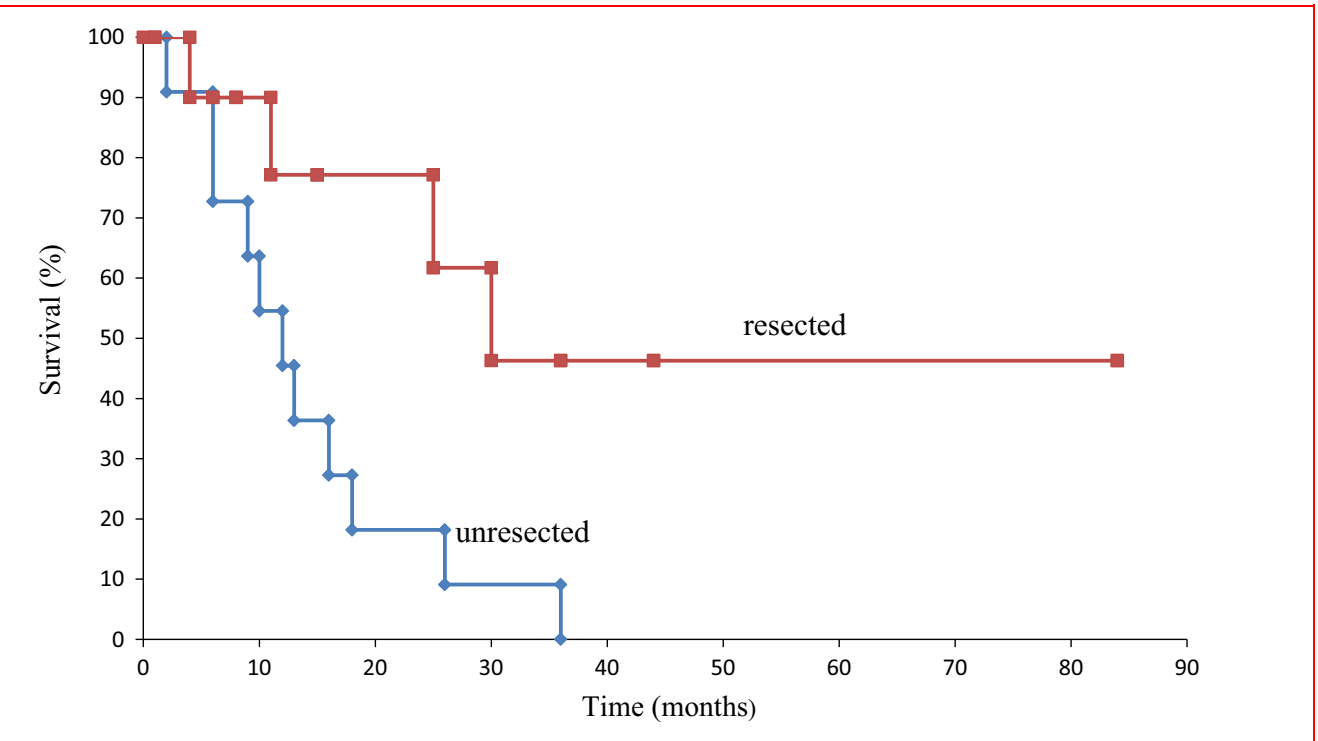

survival. Therefore, multivariate analysis for DFI could not have been investigated.

\section{Discussion}

The 5-year survival rate reported after surgical resection of PDAC is approximately $20 \%$ [11]. Most patients develop recurrence within 1 or 2 years after tumor removal [3, 12, 13]. The surgical mortality rate associated with pancreatectomy has decreased to less than $5 \%$ despite high morbidity rates and recent improvements in operative technique and perioperative management that have resulted in an increase in the number of long-term survivors after pancreatectomy [14-20]. Thus, there have been some recent reports regarding cases of remnant pancreatic cancer after pancreatectomy [21-24]. We evaluated clinicopathological findings of the remnant pancreatic cancer in survivors of PDAC.

It is difficult to define whether a pancreatic carcinoma developing in the remnant pancreas after a pancreatectomy for PDA is a local recurrence or a newly developed primary cancer [2]. The remnant pancreatic cancer was defined in this study according to those criteria mentioned earlier. In the literature, the time interval from primary PDA to remnant pancreatic cancer ranges from 12 to 89 months (mean 37.6 months), using our definition (Table 3) [1, 2, 21-30]. On the other hand, the time interval in our studied cases ranged from 15 to 240 months (mean 74.2 months) (Table 2), which is much longer than the previous reports. This result suggests that long-term follow-up after surgery for PDAC may be needed even beyond 5 years to monitor for remnant pancreatic cancer. In Japan, postoperative follow-up of patients with resected pancreatic cancer by means of CT or MRI examination every 3-6 months is generally warranted and covered by insurance. Because most patients with resected pancreatic cancer are likely to develop recurrence soon after resection, an intensive follow-up schedule is considered necessary to find recurrence in a remnant pancreas. Whether such intensive follow-up could be performed for the long term may be debatable when considering cost-effectiveness. The results of this study indicated that a newly developed cancer in the remnant pancreas could be detected by performing CT or MRI examination every 6-12 months for patients having survived for 5 years. Such long-term survivors could be few, but it is important to implement intensive follow-up beyond 5 years for such patients.

The same pathological differentiation of tumors between primary and second operation in our study was recognized in $8(67 \%)$ of the 12 resected cases, consistent with a previous report indicating $16(69.6 \%)$ of the 23 described cases as listed in Table 2. Launois et al. [31] observed $32 \%$ of multifocal carcinomas of the pancreas in a series of 47 total pancreatectomies for patients with PDAC. Likewise, a considerably high incidence of multicentric precancerous foci in the pancreas has been documented in patients with PDAC [2]. In PDAC, multicentric lesions were found in 16-34 \% of cases [32-35], implying that a minute cancerous focus is likely to exist in the remnant pancreas at the time of the initial surgery [22].

These results suggest that multicentric metachronous pancreatic cancers may develop in the remnant pancreas. Kleff et al. [10] reported that 7 (3.1\%) of the 227 patients who underwent initial pancreatic resection for pancreatic cancer developed remnant pancreatic cancer, consistent with the incidence of remnant pancreatic cancer in our 


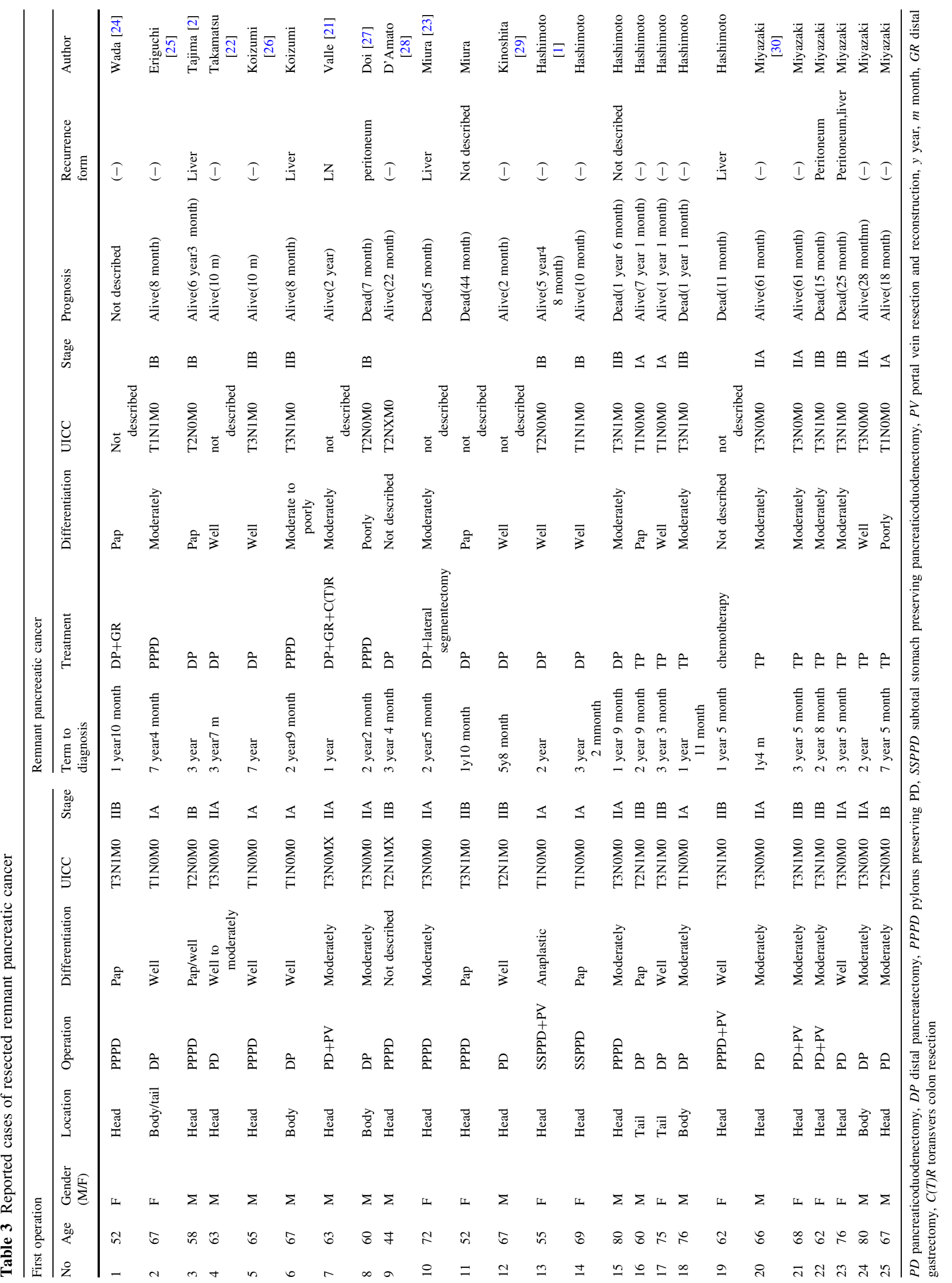


results. Therefore, multicentric foci of PDAC may develop metachronously not only after a short interval but also after a longer interval as a new primary cancer.

Miyazaki et al. [30]. reported that repetitive pancreatectomy may be beneficial for the prognosis in selected patients with isolated local recurrence in the remnant pancreas after primary pancreatectomy for pancreatic cancer without increased operative morbidity or mortality. They recognized 11 of 67 patients with isolated local recurrences only in the remnant pancreas who underwent repetitive pancreatectomies. Moreover, at the primary operation, 6 (67\%) of the 9 patients with R0 resection had the same pathological features as in our study.

In this study, we showed that patients with remnant pancreatic cancers who were resected had a better prognosis than those that were unresected. This suggests that remnant pancreatectomy for pancreatic cancer is feasible and may prolong survival. Although early discovery of remnant pancreatic cancer would be difficult, adequate interval follow-up with imaging examinations is important. Further studies are required to elucidate the carcinogenic mechanism in the remnant pancreas.

In conclusion, survivors after curative resection for pancreatic cancer should receive follow-up for the remnant pancreas for an extended period. Aggressive resection of the remnant pancreas should be considered for a more favorable prognosis of patients with PDAC.

Acknowledgements No financial support was received for this study.

\section{Compliance with ethical standards}

Conflicts of Interest The authors declare no conflicts of interest associated with this study.

Open Access This article is distributed under the terms of the Creative Commons Attribution 4.0 International License (http://crea tivecommons.org/licenses/by/4.0/), which permits unrestricted use, distribution, and reproduction in any medium, provided you give appropriate credit to the original author(s) and the source, provide a link to the Creative Commons license, and indicate if changes were made.

\section{References}

1. Hashimoto D, Chikamoto A, Ohmuraya M et al (2014) Pancreatic cancer in the remnant pancreas following primary pancreatic resection. Surg Today 44:1313-1320

2. Tajima Y, Kuroki T, Ohno T et al (2008) Resectable carcinoma developing in the remnant pancreas 3 years after pylorus-preserving pancreaticoduodenectomy for invasive ductal carcinoma of the pancreas. Pancreas 36:324-327

3. Sperti C, Pasquali C, Piccoli A et al (1997) Recurrence after resection for ductal adenocarcinoma of the pancreas. World $\mathrm{J}$ Surg 21:195-200
4. Kayahara M, Nagakawa T, Ueno K et al (1993) An evaluation of radical resection for pancreatic cancer based on the mode of recurrence as determined by autopsy and diagnostic imaging. Cancer 72:2118-2123

5. Westerdahl J, Andren-Sandberg A, Ihse I (1993) Recurrence of exocrine pancreatic cancer-Local or hepatic? Hepatogastroenterology 40:384-387

6. Griffin JF, Smalley SR, Jewell W et al (1990) Patterns of failure after curative resection of pancreatic carcinoma. Cancer 66:56-61

7. Smeenk HG, Incrocci L, Kazemier G et al (2005) Adjuvant 5-FUbased chemoradiotherapy for patients undergoing R-1/R-2 resections for pancreatic cancer. Dig Surg 22:321-328

8. Smeenk HG, Tran TC, Erdmann J et al (2005) Survival after surgical management of pancreatic adenocarcinoma: does curative and radical surgery truly exist? Langenbecks Arch Surg 390:94-103

9. Tepper J, Nardi G, Sutt H (1976) Carcinoma of the pancreas: review of MGH experience from 1963 to 1973: analysis of surgical failure and implications for radiation therapy. Cancer 37:1519-1524

10. Kleeff J, Reiser C, Hinz U et al (2007) Surgery for recurrent pancreatic ductal adenocarcinoma. Ann Surg 245:566-572

11. Yeo CJ, Cameron JL, Lillemoe KD et al (1995) Pancreaticoduodenectomy for cancer of the head of the pancreas 201 Patients. Ann Surg 221:721-731 (discussion 731-733)

12. Ishikawa $\mathrm{O}$, Wada $\mathrm{H}$, Ohigashi $\mathrm{H}$ et al (2003) Postoperative cytology for drained fluid from the pancreatic bed after "curative" resection of pancreatic cancers: does it predict both the patient's prognosis and the site of cancer recurrence? Ann Surg 238:103-110

13. Kobayashi T, Sato Y, Hirukawa H et al (2012) Total pancreatectomy combined with partial pancreas autotransplantation for recurrent pancreatic cancer: a case report. Transplant Proc 44:1176-1179

14. Balcom JH 4th, Rattner DW, Warshaw AL et al (2001) Ten-year experience with 733 pancreatic resections. Changing indications, older patients, and decreasing length of hospitalization. Arch Surg 136:391-398

15. Butturini G, Marcucci S, Morinari E et al (2006) Complications after pancreaticoduodenectomy: the problem of current definitions. J Hepatobiliary Pancreat Surg 13:207-211

16. Trede M, Saeger HD, Schwall G et al (1998) Resection of pancreatic cancer: surgical achievements. Langenbecks Arch Surg 383:121-128

17. Yeo CJ, Cameron JL, Sohn TA et al (1997) Six hundred fifty consecutive pancreaticoduodenectomies in the 1990s: pathology, complications, and outcomes. Ann Surg 226:248-257

18. Klinkenbijl JH, van der Schelling GP, Hop WC et al (1992) The advantages of pylorus-preserving pancreatoduodenectomy in malignant disease of the pancreas and periampullary region. Ann Surg 216:142-145

19. Yeo CJ, Cameron JL, Maher MM et al (1998) Periampullary adenocarcinoma: analysis of 5-year survivors. Ann Surg 227:821-831

20. Jimenez RE, Fernandez-del Castillo C, Rattner DW et al (2000) Outcome of pancreaticoduodenectomy with pylorus preservation or with antrectomy in the treatment of chronic pancreatitis. Ann Surg 231:293-300

21. Dalla Valle R, Mancini C, Crafa P et al (2006) Pancreatic carcinoma recurrence in the remnant pancreas after a pancreaticoduodenectomy. JOP 7:473-477

22. Takamatsu S, Ban D, Irie T et al (2005) Resection of a cancer developing in the remnant pancreas after a pancreaticoduodenectomy for pancreas head cancer. J Gastrointest Surg 9:263-269 
23. Miura F, Takada T, Amano H et al (2007) Repeated pancreatectomy after pancreatoduodenectomy. J Gastrointest Surg 11:179-186

24. Wada K, Takada T, Yasuda H et al (2001) A repeated pancreatectomy in the remnant pancreas 22 months after pylorus-preserving pancreatoduodenectomy for pancreatic adenocarcinoma. J Hepatobiliary Pancreat Surg 8:174-178

25. Eriguchi N, Aoyagi S, Imayama H et al (2000) Resectable carcinoma of the pancreatic head developing 7 years and 4 months after distal pancreatectomy for carcinoma of the pancreatic tail. J Hepatobiliary Pancreat Surg 7:316-320

26. Koizumi M, Sata N, Kasahara N et al (2010) Remnant pancreatectomy for recurrent or metachronous pancreatic carcinoma detected by FDG-PET: two case reports. JOP 11:36-40

27. Doi R, Ikeda H, Kobayashi $H$ et al (2002) Carcinoma in the remnant pancreas after distal pancreatectomy for carcinoma. Eur J Surg Suppl 588:62-65

28. D'Amato A, Gentili V, Santella S et al (2002) Carcinoma of the pancreatic remnant developing after pancreaticoduodenectomy for adenocarcinoma of the head of pancreas. Chir Ital 54:539-544

29. Kinoshita H, Yamade N, Nakai H et al (2011) Successful resection of pancreatic carcinoma recurrence in the remnant pancreas after a pancreaticoduodenectomy. Hepatogastroenterology 58:1406-1408
30. Miyazaki M, Yoshitomi H, Shimizu H et al (2014) Repeat pancreatectomy for pancreatic ductal cancer recurrence in the remnant pancreas after initial pancreatectomy: is it worthwhile. Surgery 155:58-66

31. Launois B, Franci J, Bardaxoglou E et al (1993) Total pancreatectomy for ductal adenocarcinoma of the pancreas with special reference to resection of the portal vein and multicentric cancer. World J Surg 17:122-126. doi:10.1007/BF01655724 (discussion 126-127)

32. Ihse I, Lilja P, Arnesjo B et al (1977) Total pancreatectomy for cancer. An appraisal of 65 cases. Ann Surg 186:675-680

33. Tryka AF, Brooks JR (1979) Histopathology in the evaluation of total pancreatectomy for ductal carcinoma. Ann Surg 190:373-381

34. van Heerden JA, ReMine WH, Weiland LH et al (1981) Total pancreatectomy for ductal adenocarcinoma of the pancreas. Mayo Clinic experience. Am J Surg 142:308-311

35. SarrMG Behrns KE, van Heerden JA (1993) Total pancreatectomy.An objective analysis of its use in pancreatic cancer. Hepatogastroenterology 40:418-421 